Original Research Paper

\title{
Modern Walking Robots: A Brief Overview
}

\section{Vyacheslav Lyashenko ${ }^{1}$, M. Ayaz Ahmad ${ }^{2}$, Nataliya Belova ${ }^{3}$, Svitlana Sotnik ${ }^{4}$}

${ }^{1}$ Department of Media Systems and Technology, Kharkiv National University of Radio Electronics, Ukraine.

${ }^{2}$ Department of Physics, Faculty of Science, University of Tabuk, Saudi Arabia.

${ }^{3}$ Department of Informatics, Kharkiv National University of Radio Electronics, Ukraine.

${ }^{4}$ Department of Computer-Integrated Technologies, Automation and Mechatronics, Kharkiv National University of Radio Electronics, Ukraine.

Article history

Received:

27.07.2021

Revised:

17.08.2021

Accepted:

21.08.2021

*Corresponding Author:

Vyacheslav Lyashenko

Email:

lyashenko.vyacheslav@gmail.com

This is an open access article, licensed under: $\mathrm{CC}-\mathrm{BY}-\mathrm{SA}$
Abstract: In this review, we would like to present some of the most interesting modern designs of walking robots: bipedal, quadropedal, hexopedal, and octopods. Their advantages and disadvantages are highlighted. It has been determined that structures with eight or more limbs are ineffective due to high level of electricity consumption. The use of more than six number of legs does not give noticeable advantages in profile cross-country ability or maneuverability, however, it allows to reduce the forces and moments of inertia forces due to decrease in mode coefficient (ratio of time spent by propulsor in support to time of entire step), and, consequently, smoother leg movements in swing phase.

Keywords: Advantages, Design, Disadvantages, Robot, Walking. 
Vyacheslav Lyashenko, M. Ayaz Ahmad, Nataliya Belova, Svitlana Sotnik

Modern Walking Robots: A Brief Overview

International Journal of Recent Technology and Applied Science, vol 3, no. 2, pp. 32-39, September 2021. DOI: 10.36079/lamintang.ijortas-0302.252

\section{Introduction}

Over past two decades, a considerable number of walking robots (WR) have been implemented, but all of them are still being improved.

Robots capable of walking with balance. Walking so familiar to humans is a process that has proven difficult to replicate on robotic platforms. Modern robots surprise they not only walk, but run, jump and crawl.

There are many options for design of WR: with two, four, six, eight or more limbs. More legs WR has, more points of support robot can use during movement. The sensor system allows walking robot to adapt its foot position to uneven terrain.

Many robots designed to replace humans in hazardous activities have enormous potential [1] [2] [3] [4] [5] [6]. Research and development in field of walking robots is carried out in all developed countries of world. The results of research on walking robots have led to creation of numerous samples of such robots, number of which is now growing every day.

\section{Materials and Methods}

\subsection{Related Work}

At present, numerous robots are devoted to problem of walking robots, in which the following are considered: WR design [7] [8] [9] [10] [11], motion algorithms [12] [13], stability of robot [14] [15], construction of a motion control system [16] [17], etc.

In [7], problems of creating walking robots are considered, which have advantages over wheeled robots when overcoming obstacles while in [8] is devoted to kinematic analysis, mechanical design and production of four-legged walking insect robot with eight degrees of freedom and two degrees of freedom for each leg. In [9], design and testing of walking robot is described. The authors construct bipedal walk where each robotic leg was equipped with six servos.

In [10] design and construction of six legged robots are described. Design, construction, and rough-terrain locomotion control of novel hexapod walking robot with four degrees of freedom per are described in [11].

In [12], motion algorithms are considered and classified into 3 groups: non-adaptive, self-learning algorithms, etc.

In [13] presents an algorithm for fuzzy control of robot walking under water when it collides with an obstacle without given parameters. Based on algorithms for controlling fuzzy movements, typical leg movements were developed, which are autonomously performed by robot in order to eliminate emergency situations.

In [14], an analysis of static stability was carried out, which provided information about adequacy of design and possibilities of controlling robot. The study included analysis of typical robot postures aimed at maintaining static stability.

The authors presented concept of hexa-quad bimorph walking robot. Tip-over stability analysis of a pelvic support walking robot are discussed in [15]. A new method is proposed to predict possibility of tipping over and evaluate stability of robot based on statics model, dynamics model, and zeromoment point (ZMP) theory. Some features of route planning as basis in a mobile robot are described in [16]. Motion planner which takes into account terrain types when planning the motion of robot are proposed in [17].

\subsection{Types of Walking Robots}

The impressive successes of two- and four-legged WRs, but development continues and development with six legs is often found, and eight-legged robots and robots with a large number of legs are used less often [7].

1. WR bipedal construction. The robot actuator consists of body and two legs, has several degrees of mobility. Such robots are easier to implement, since it is based on and repeats human motor skills (Figure 1). Such robots can have a dynamic body that allows robot to use weight and structure of its own body to maintain balance and walk on uneven surfaces.

2. The largest robot in the world with bipedal structure is Gundam Dock, which is $18 \mathrm{~m}$ high and weighs 25 tons. It has 24 degrees of freedom. The robot is driven by electric motors (Figure 2) [18]. 


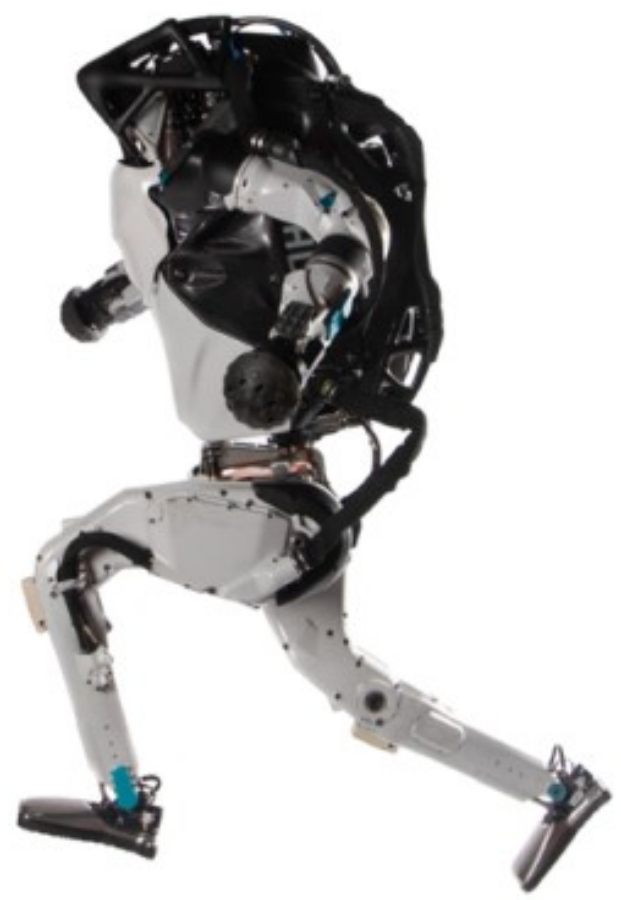

Figure 1. Bipedal Robots: Boston Dynamics

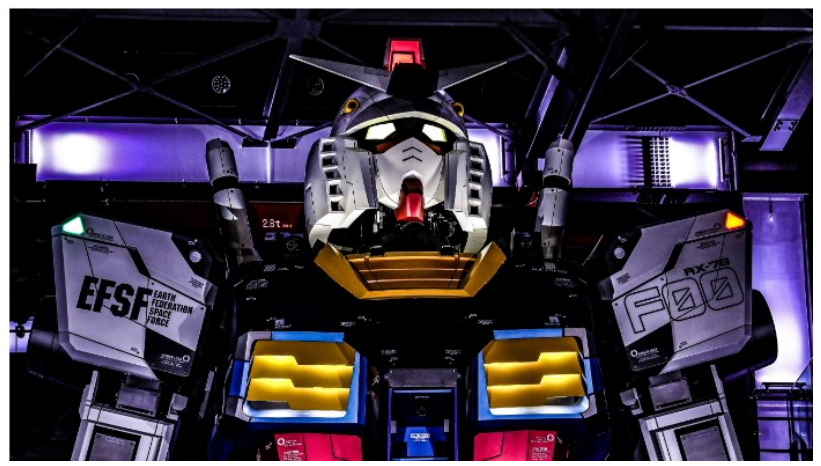

Figure 2. Bipedal Robots: Gundam Dock

3. The quadropedal design of the WR (four-legged) has number of limbs already more than two, but less than six. Thanks to this, center of gravity is at intersection of limbs and does not require special means to maintain balance while moving. Such system is easier to implement and copes better when navigating difficult terrain.

4. Few representatives of robot's world are able to cope with high obstacles, but such robots still exist. For example, robots can climb 45-degree slope of Unitree (Figure 3) [19] [20] and a robot by Boston Dynamics - it is oriented in space while it is assisted by laser rangefinders, which are located on its back, as well as four cameras on its head (Figure 4). The robot has 23 degrees of freedom (DoF): 5 DoF in each leg, 2 DoF for dual laser rangefinder sensors, and $1 \mathrm{DoF}$ for head. Four manipulators enable robot to maintain balance and cross rather difficult areas with uneven relief [21]. 


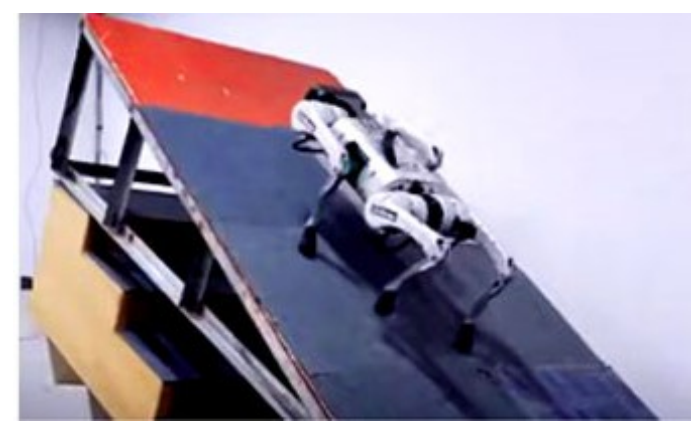

Figure 3. Four-legged Robots: Unitree

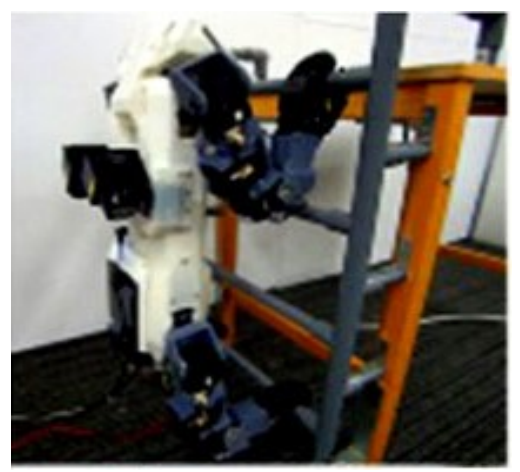

Figure 4. Four-legged Robots: Boston Dynamics

5. Hexopedal WR design (six-legged) - has a symmetrical shape and additional supporting limbs. The center of gravity when walking is maintained close to inactive position. Also, movement of all limbs can be carried out in two stages, 3 legs for each, which is difficult to do with a quadropedal design. However, there is also an increase in energy consumption and the size of structure [22].

6. A feature of such robots is that they may have different widths of leg mounts location (Figure 5) [23]. In this case, robot alternately rests on three of six legs: two non-adjacent angled legs on one side of body and one central on other. That is, center legs on both sides have a greater load than corner legs. To reduce this load, the central legs are located at greater distance from longitudinal axis of symmetry than angular legs.

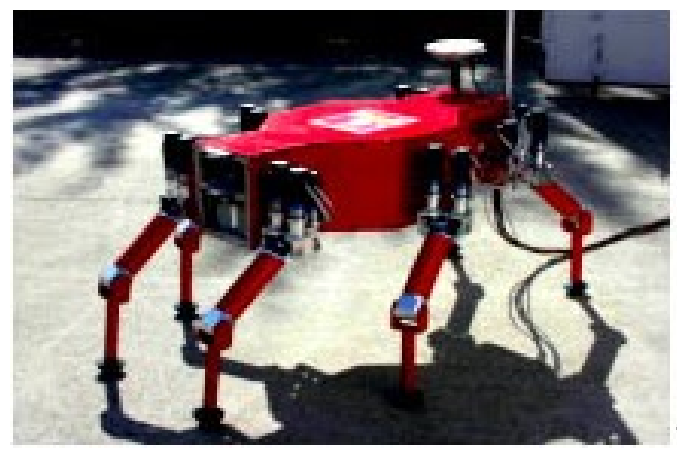

Figure 5. Six-legged Robots: Robot with Different Widths Leg Bindings 
7. Great example would be RHex, bio-inspired hex robot built for traversing terrain. He can ride on stones, mud, sand, snow and railway tracks, and even climb stairs and descents up to 45 degrees (Figure 6) [24] [25].

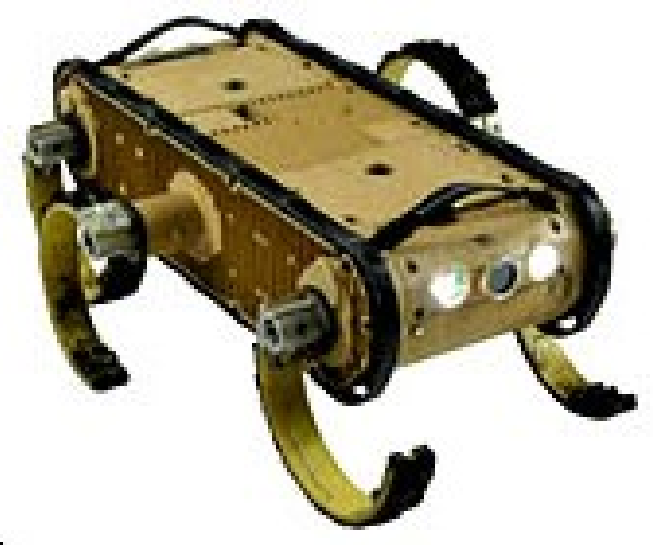

Figure 6. Six-legged Robots: RHex

8. Octopod (eight-legged robot) is like prototypes of spiders, scorpions, crab, etc. They are used for: scientific missions, moving in pipes, for mine clearance, that is, to obtain information about an object, for example, monitoring and moving often in hard-to-reach, extreme and unsafe places [26] [27] [28] [29]. Figure 7 shows typical example of an octopod [27].

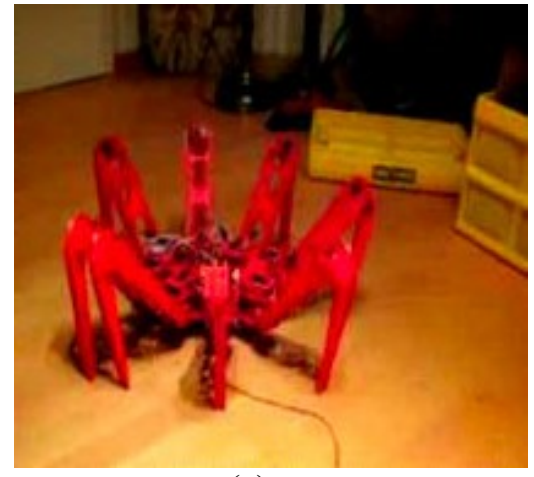

(a)

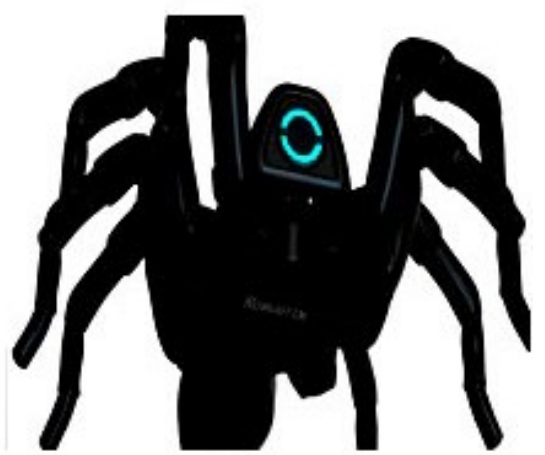

(b)

Figure 7. Eight-legged Robots:

(a) Octopod Robot

(b) T8X Robot

9. T8X is only robot in market that combines so much resemblance to real spider with fine movements, programmability, and customizability. With 26 servo motors packed inside robot and powered by proprietary Bigfoot Robotics Engine, which contains advanced 
robotics algorithms for controlling multi-legged walking robots, there are endless possibilities for types of bio-inspired [28].

10. Most of walking robots have adaptive software control, in which program is set either in form of trajectories ready for processing by drives for each of manipulation system coordinates, or in form of trajectories in coordinates of working area, which are then converted in real time into coordinates of mobility degrees of robot manipulation system [23].

3. Advantages and disadvantages of walking robots

Thus, let us highlight advantages of using WR as whole:

1. security

2. versatility of tasks performed

3. movement on rough surfaces, stairs, slopes, stones, snow, railways

4. resemblance to person

And, their main disadvantage may be complexity of design and control system.

Today, to greater extent, research related to creation of WR is aimed precisely at ensuring movement over rough terrain. More legs, the easier it is to control such WRs [7].

\subsection{WR Bipedal Structures}

Advantage:

$\circ$ Are able to run, jump, step over and even dance

- Ability to step over;

- Anthropomorphic mechanisms are used mainly for development of bipedal robots

- Added ability to rotate robot around vertical axis in "hip joint"

- Adaptation of foot to ground.

Disadvantage:

- Center of gravity is similar to person and is at high level from surface, and this leads to fact that such structure can be easily turned over, therefore, one should think about mechanisms of stabilization of such robots.

\subsection{WR Quadropedal Structures}

Advantage:

- Able to run, jump, crawl

- There are robots capable of moving over rough terrain, climbing inclined slopes and Disadvantage: vertical stairs, and at same time they can afford to increase speed of movement

- Impossibility of changing manner of robots walking movement on rough terrain. Robot must be trained for each individual ladder

- Problem for robots is difficulty of maintaining balance: when moving vertically, center of gravity of mechanism deviates backward and it is very difficult for robot to hold on

- To ensure possibility of movement manner changing, several independent drives are introduced into design of walking machine.

\subsection{WR Hexopedic Structures}

Advantage:

$\circ$ Different gait options.

- Hexapod-like structures, allow you to obtain maximum accuracy of actuators with minimum travel time due to introduction of parallelism in processes of measurement, calculation, movement and use of high-precision motors.

Disadvantage:

- Such mechanisms can have more complex kinematic scheme, which requires more developed control algorithms and solution of new, complex optimization problems that ensure implementation of optimal trajectories of movements without jamming. 
Vyacheslav Lyashenko, M. Ayaz Ahmad, Nataliya Belova, Svitlana Sotnik

Modern Walking Robots: A Brief Overview

International Journal of Recent Technology and Applied Science, vol 3, no. 2, pp. 32-39, September 2021. DOI: 10.36079/lamintang.ijortas-0302.252

\subsection{Eight-Legged WR Designs}

Advantage:

$\circ$ They have greatest stability compared to other robots

- Maneuverable

Disadvantage:

$\circ$ There may be high level of electricity consumption.

The number of limbs, maneuverability and patency of WR determines design of limb itself. In 2drive design, weight and energy consumption are reduced, but working area of limb is reduced, which negatively affects maneuverability and cross-country ability when driving on uneven surfaces. In design of three links with three drives, working area is significantly expanded [23].

\section{Conclusions}

The paper briefly discusses modern robots: bipedal, quadrupedal, hexopedal and octopods. Their advantages and disadvantages are highlighted.

It has been determined that structures with eight or more limbs are ineffective due to high level of electricity consumption. Four-legged robots consume less energy, but have less static stability, they are more limited in choosing a route when moving over rough terrain, while six-legged robots represent a compromise between four and eight-legged.

The use of more than six number of legs does not give noticeable advantages in profile crosscountry ability or maneuverability, however, it allows to reduce forces and moments of inertia forces due to decrease in mode coefficient (ratio of propulsion time to entire step time), and, therefore, smoother leg movements in swing phase. All robots are equipped with microprocessor controllers.

\section{References}

[1] R. Matarneh, S. Maksymova, Zh. Deineko, and V. Lyashenko, "Building Robot Voice Control Training Methodology Using Artificial Neural Net", International Journal of Civil Engineering and Technology, vol. 8, no. 10, pp. 523-532, 2017.

[2] S. Maksymova, R. Matarneh, V. Lyashenko, and N. Belova, "Voice Control for an Industrial Robot as a Combination of Various Robotic Assembly Process Models", Journal of Computer and Communications, vol. 5, no. 11, pp. 1-15, 2017. doi: 10.4236/jcc.2017.511001.

[3] S. Maksymova, R. Matarneh, and V. Lyashenko, "Software for Voice Control Robot: Example of Implementation", Open Access Library Journal, vol. 4, no. 8, pp. 1-12, 2017. doi: 10.4236/oalib.1103848.

[4] V. Lyashenko, and S. Sotnik, "Analysis of Basic Principles for Sensor System Design Process Mobile Robots", Journal La Multiapp, vol. 1, no. 4, pp. 1-6, 2020. doi: 10.37899/journallamultiapp.v1i4.237.

[5] R. Matarneh, S. Maksymova, O. Zeleniy, and V. Lyashenko, "Voice Control for Flexible Medicine Robot", International Journal of ComputerTrends and Technology (IJCTT), vol. 56, no. 1, pp. 1-5, 2018. doi: 10.14445/22312803/IJCTT-V56P101.

[6] R. Matarneh, S. Sotnik, Z. Deineko, and V. Lyashenko, "Development of an Information Model for Industrial Robots Actuators", IOSR Journal of Mechanical and Civil Engineering (IOSR-JMCE), vol. 16, no. 1, pp. 61-67, 2019. doi: 10.9790/1684-1601056167.

[7] M. B. Ignat'ev, and et al., "Shagayushchie roboty-problemy i perspektivy", Innovatika $i$ ekspertiza: nauchnye trudy, vol. 2, pp. 128-137, 2016.

[8] P. M. James, A. Prakash, V. Kalburgi, and P. Sreedharan, "Design, analysis, manufacturing of four-legged walking robot with insect type leg", Materials Today: Proceedings, 2020. doi: 10.1016/j.matpr.2020.10.286

[9] P. Nowak, A. Milecki, and M. Białek, "Construction and Control of the Bipedal Walking Robot", In MATEC Web of Conferences, vol. 252, p. 02009, 2019. doi: 10.1051/matecconf/201925202009.

[10] G. Bhanuteja, V. Mudkavi, G. Sharma, and M. K. E. Nidagundi, "Design and Construction of Six Legged Robot", In 2018 International Conference on Design Innovations for 3Cs Compute Communicate Control (ICDI3C), pp. 84-87, 2018. doi: 10.1109/ICDI3C.2018.00026. 
Vyacheslav Lyashenko, M. Ayaz Ahmad, Nataliya Belova, Svitlana Sotnik

Modern Walking Robots: A Brief Overview

International Journal of Recent Technology and Applied Science, vol 3, no. 2, pp. 32-39, September 2021. DOI: 10.36079/lamintang.ijortas-0302.252

[11] P. Čížek, M. Zoula, and J. Faigl, "Design, Construction, and Rough-Terrain Locomotion Control of Novel Hexapod Walking Robot With Four Degrees of Freedom Per Leg", IEEE Access, vol. 9, pp. 17866-17881, 2021. doi: 10.1109/ACCESS.2021.3053492.

[12] E. Z. Moore, "Leg Design and Stair Climbing Control for the RHex Robotic Hexapod", Department of Mechanical Engineering McGill University, 2002.

[13] V. V. Chernyshev, V. V. Arykantsev, and I. P. Vershinina, "Fuzzy control of underwater walking robot during obstacle collision without pre-defined parameters", Lecture Notes in Electrical Engineering, vol. 641, pp. 347-356, 2019. doi: 10.1007/978-3-030-39225-3_38.

[14] D. Wojtkowiak, K. Talaśka, I. Malujda, J. Górecki, and D. Wilczyński, "Modelling and static stability analyses of the hexa-quad bimorph walking robot", In MATEC Web of Conferences, vol. 254, p. 02029, 2019. doi: 10.1051/matecconf/201925402029.

[15] Y. Han, S. Guo, L. Zhang, F. J. Xi, and W. Lu, "Tip-over stability analysis of a pelvic support walking robot", Journal of healthcare engineering, vol. 2020, Article ID 1506250, 9 pages, 2020. doi: 10.1155/2020/1506250.

[16] S. Sotnik, S. Kh. Mustafa, M. A. Ahmad, V. Lyashenko, and O. Zeleniy, "Some Features of Route Planning as the Basis in a Mobile Robot", International Journal of Emerging Trends in Engineering Research (IJETER), vol. 8, no. 5, pp. 2074-2079, 2020. doi: 10.30534/ijeter/2020/97852020.

[17] S. Bartoszyk, P. Kasprzak, and D. Belter,'Terrain-aware motion planning for a walking robot", In 11th International Workshop on Robot Motion and Control (RoMoCo), pp. 29-34, 2017. doi: 10.1109/RoMoCo.2017.8003889.

[18] N. Shibata, "18-meter moving Gundam robot towers over Yokohama port", Nikkei Asia, 2020, [Online]. Available: https://asia.nikkei.com/Business/Media-Entertainment/18-meter-movingGundam-robot-towers-over-Yokohama-port. [Accessed: July 21, 2021].

[19] L. Jiang, J. Guo, B. Su, P. Xu, and R. Dang, "AI in Locomotion: Quadruped Bionic Mobile Robot", In International Conference on Cognitive Systems and Signal Processing, pp. 445-451, 2018. doi: 10.1007/978-981-13-7983-3_39.

[20] J. J. Driessen, and R. Orsolino, "Improving Robustness of Legged Robots against Mechanical Shock Using Impulsive Dynamics", Frontiers in Mechanical Engineering, vol. 6, pp. 100, 2021. doi: $10.3389 /$ fmech.2020.601922.

[21] E. Ackerman, "Quadruped Robots Can Climb Ladders Now", IEEE Spectrum, 2019.

[22] G. S. Vasil'yanov, and A. E. Vasil'ev, "Razrabotka i issledovanie simmetrichnoj shagayushchej robototekhnicheskoj platformy so vstraivaemym ustrojstvom upravleniya", Informatika $i$ kibernetika (ComCon-2016), pp. 45-47, 2016.

[23] E. V. Poezzhaeva, and P. V. Smolonogin, "Shagayushchie roboty s konturnoj sistemoj upravleniya", Problemy mekhaniki sovremennyh mashin, pp. 227-233, 2012.

[24] M. Martone, C. Pavlov, A. Zeloof, V. Bahl, and A. M. Johnson, "Enhancing the Vertical Mobility of a Robot Hexapod Using Microspines", arXiv preprint arXiv:1906.04811, 2019.

[25] S. F. Roberts, and D. E. Koditschek, "Mechanical and virtual compliance for robot locomotion in a compliant world", ICRA, 2019.

[26] D. Grzelczyk, and J. Awrejcewicz, "Modeling and control of an eight-legged walking robot driven by different gait generators", International Journal of Structural Stability and Dynamics, vol. 19, no. 05, p. 1941009, 2019. doi: 10.1142/S0219455419410098.

[27] I. Olaronke, O. Oluwaseun, and I. A. Rhoda, "Comprehensive Study of Climbing and Walking Robots (CLWAR) Paradigms", International Journal of Applied Information Systems (IJAIS), vol. 12, no. 20, pp. 11-22, 2019.

[28] M. Gianni, "Towards Expendable Robot Teaming in Extreme Environments", International Journal of Mechanical Engineering and Robotics Research, vol. 8, no. 6, pp. 830-838, 2019. doi: 10.18178/ijmerr.8.6.830-838.

[29] S. N. Teli, R. Agarwal, D. Bagul, P. Badawane, and R. Bandre, "Design and Fabrication of Multi Legged Robot", International Research Journal of Engineering and Technology, vol. 6, no. 3, pp. 1-11, 2019. 